\title{
ДИСКУРС
}

\author{
М.Е. Бойко
}

\section{ОПЕРАТОРНЫЙ ПОДХОД В ТЕОРИИ ЛИТЕРАТУРЫ: НАРРАТИВНЫЕ ОПЕРАТОРЫ, ИХ СВОЙСТВА И ПРИМЕНЕНИЕ}

Аннотация. Предметом исследования является решение проблемы соотношения художественного вымысла и реальности с помощью «операторного подхода». Анализируются причины, побудившие исследователей к введению в теорию литературы «нарративных операторов» и, в частности, "оператора вымысла» (fiction-operator). Рассматриваются аргументы Г.-Н. Кастанеды против операторного подхода и его тезис о том, что различие между утверждениями о вымышленном мире и утверждениями о действительности заключается в характере предикации. Исследуются свойства нарративных операторов, вводится понятие "нарративно-аналитического оператора», обладающего свойством линейности. Основной метод исследования - операторный подход, основанный на аналогии с операторным исчислением в математике и естествознании. Демонстрируется, что операторный подход в теории литературы обладает большой эвристической силой, позволяет фрормализовать некоторые сложные проблемы, даёт ясные, строгие и эффективные решения. Доказывается, что теория Г.-Н. Кастанеды об амбивалентности связки не противоречит "операторному решению», а содержится в числе его логических следствий. Констатируется, что операторный подход является одним из мощнейших инструментов в современной теории литературы, и очерчивается ряд актуальных проблем, для решения которых использование операторного подхода может оказаться плодотворным.

Ключевые слова: Дэвид Льюис, нарративный оператор, нарратология, семантика, семантический оператор, структурализм, теория литературы, фикциональный дискурс, формализация, художественный вымысел.

Abstract. The subject of the research is the solution of the problem regarding the relationship betwen fiction and reailty by using the so called 'operator approach'. Boyko analyzes the reasons that encouraged researchers to introduce 'narrative operators' in the theory of literature, in particular, the 'fiction-operator'. He also analyzes arguments of Hector-Neri Castañeda against the operator approach as well as his thesis that the difference between fictional statements and reality statements is the nature of predication. Boyko analyzes the features of narrative approaches and introduces the term 'narrative-analytical operator' that has the feature of linearity. The main research method used by the author is the operator approach based on the analogy with the operator calculus in mathematics and natural sciences. It is demonstrated that the operator approach to the theory of literature has a great heuristical power and allows to formalize certain complex issues as well as to provide clear, strict and efficient solutions. The author proves that the ambivalency theory of HectorNeri Castañeda does not oppose to the operator approach but on the contrary constitutes one of its logical consequences. It is stated that the operator approach is one of the most powerful instruments in the modern theory of literature. The author of the article also outlines a range of important issues that can be solved by the operator approach.

Key words: fictional discourse, theory of literature, structuralism, semantic operator, semantics, narratology, narrative operator, David Lewis, formalization, fiction.

\section{1. Задача исследования}

Использование в теории литературы точных методов, перенесённых из математики или естествознания, имеет почтенную традицию - достаточно упомянуть бурные исследования в период расцвета формализма и структурализма. Широкое применение в гуманитарных исследованиях получил научный инструментарий, заимствованный из ма- тематической логики, математической статистики, теории вероятностей, комбинаторики, функционального анализа, линейной алгебры. Отдельно отметим плодотворное использование модальной логики и теории модальностей (например, [1] и [2]), семантики возможных миров (см. обзор в [3]), мультиверсного подхода (см. обзор в [4]) и операторного подхода, которому посвящено данное исследование. 
В англоязычных гуманитарных исследованиях, находящихся под сильным влиянием аналитической философии, интерес к точным методам поддерживается на стабильно высоком уровне. К сожалению, этого нельзя сказать о гуманитарных исследованиях в европейской («континентальной») и, в частности, российской науке. Приходится констатировать, что чрезмерные надежды, возлагавшиеся на формальные методы в период наивысшей популярности структурализма, привели к последующему разочарованию и постмодернистской «реакции» с её иррациональными тенденциями. Вероятно, этим можно объяснить слабый интерес к операторному подходу среди европейских и, в частности, российских теоретиков литературы.

Данным исследованием мы хотели бы оживить интерес к операторному подходу в теории литературы и для этой цели проанализировать ряд вопросов:

1) Как возникла идея использовать операторный подход в теории литературы?

2) Какие проблемы в теории литературы получили удовлетворительное решение с помощью операторного подхода?

3) Для решения каких проблем в теории литературы целесообразно использовать операторный подход?

\section{2. Проблема соотношения вымысла/ реальности и «операторное решение»}

Пожалуй, самую остроумную постановку проблемы соотношения художественного вымысла и реальности предложил американский философ Г.-Н. Кастанеда [5, с. 69-70], но мы воспользуемся более простой формулировкой израильской исследовательницы Р. Ронен [3, с. 33]. Представим, что в метеорологической сводке мы встречаем предложение «В Лондоне шёл дождь». Очевидно, что речь идёт о дожде в реальном мире. Представим также, что эту же самую фразу мы встречаем в романе Диккенса. Очевидно, что в этом случае речь идёт о дожде в вымышленном мире романа, и это предложение истинно в контексте романа Диккенса безотносительно к тому шёл или не шёл дождь в указанный день в реальном Лондоне. Но как мы узнаём о том, в каком именно мире - действительном или вымышленном - шёл дождь, если читаем совершенно идентичные предложения, одинаковые последовательности букв?

Естественно предположить, что на идентичные предложения в данном случае действует какой-то невидимый, неучтённый фактор, от которого зависит к какому миру - действительному или вымышленному - следует относить эти внешне идентичные предложения. Этот неучтённый фактор американский философ Д. Льюис (Льюиз) определил как «интенсиональный оператор» (intensional operator) [6, с. 262], т.е. как смысловой, семантический оператор. Льюис предложил рассматривать предложения, относящиеся к художественному вымыслу, как сокращения более длинных предложений, начинающихся с оператора «В таком-то художественном произведении...»: «Такое выражение представляет собой интенсиональный оператор, который может быть присоединен к предложению Р, чтобы образовать новое предложение. Но затем присоединяемый оператор может быть опущен с целью сокращения, оставляя нас с предложением, которое звучит точно так же, как исходное предложение Р, но отличается от него по смыслу» [7, с. 49]. Заметим, что за оператором, введённым Льюисом закрепилось название «нарративный оператор» [5, c. 83], а в более узком значении (применительно только к художественному вымыслу) - «оператор вымысла» (fiction-operator, fictional operator) [3, c. 33, 38]. Нарративные операторы не стоит путать с «метатекстовыми операторами», проанализированными А. Вежбицкой [8, с. 417] - это иной тип синтактико-семантических операторов, который мы не будем рассматривать в данной статье.

Льюис использовал для анализа проблемы соотношения вымысла и реальности термин «оператор», заимствовав его, очевидно, из модальной логики - по аналогии с алетическими модальными операторами «возможно» и «необходимо». Но возможна и другая аналогия - с операторами, используемыми в функциональном анализе и квантовой механике. Там операторами называются действия (отображения), ставящие в соответствие функциям из некоторого множества некоторые другие функции из этого же множества - т.е. это «функции от функций», или «функционалы» [9, с. 69]. Аналогия эта основана на том наблюдении, что текст можно рассматривать как семантическую функцию. Математический оператор, действуя на функцию, превращает её в некоторую другую функцию, - аналогично интенсиональный оператор, действуя на текст, превращает его в некоторый другой текст. Отличие нашего подхода от подхода Льюиса (Lewisian approach) состоит в том, что вторая аналогия представляется нам более предпочтительной, как с точки зрения удобства обозначений (символической нотации), так и с точки зрения эвристического потенциала.

Льюис в своей статье использует для обозначения нарративного оператора громоздкую, неудобную символическую нотацию: например, действие на предложение $\psi$ нарративного оператора «In the fiction $\mathrm{f} . . . »$ он обозначает «In f, $\psi$ » [6, с. 264] (эта символика опущена в русском переводе [7]). Но, на наш 
взгляд, это как раз тот случай, когда удобная символическая запись способна значительно прояснить суть предлагаемого Льюисом решения.

В математике и физике над обозначениями операторов, чтобы отличить их от других символов, ставится треугольная «крышечка» (циркумфлекс). Мы предлагаем сохранить эту условность и обозначать нарративный оператор символом с циркумфлексом - например, $\hat{N}$. Результат действия оператора на некоторый текст $T$ мы будем обозначать $\hat{N T}$, и это тоже есть некоторый текст. Иначе говоря, $\hat{N} T_{1}=T_{2}$.

Очевидно, что идентичные предложения в метеорологической сводке и романе Диккенса находятся под действием различных нарративных операторов. В одном случае это нарративный оператор реальности $\hat{N}_{A}$ (индекс $A$ указывает на «actual world»), заключающийся в присоединении к исходному предложению зачина «В реальном мире...», или «It is actual that...» [3, с. 39]. В другом случае это нарративный оператор вымысла $\hat{N}_{F}$ (индекс $F$ указывает на «fictional world»), заключающийся в присоединении к исходному предложению другого зачина - «В мире художественного произведения $x \ldots »$, или «In the story х...» [3, с. 38].

Пусть $P_{1}=$ «В Лондоне шёл дождь». Мы различаем по смыслу идентичные предложения, когда встречаем их в различных текстах, поскольку они находятся под действием различных нарративных операторов. Например, читая $P_{1}$ в метеорологической сводке, мы в действительности воспринимаем предложение $P_{2}: \hat{N}_{A} P_{1}=P_{2}=$ «В реальном мире $P_{1}$ », а, встречая $P_{1}$ в романе Диккенса, мы в действительности воспринимаем предложение $P_{3}: \hat{N}_{N} P_{1}=P_{3}=$ «В вымышленном мире романа Диккенса $P_{1}$ ». Идентичные предложения в этих двух случаях имеют различный смысл, поскольку $P_{2}$ не идентично $P_{3}$.

Однако сегодня можно констатировать, что столь элегантного решения проблемы соотношения художественного вымысла и реальности оказалось недостаточно, чтобы закрепить за «операторным подходом» в теории литературы статус мощного исследовательского инструмента и инициировать дальнейшее развитие этого метода. Почему?

\section{3. Критика Г.-Н. Кастанедой «операторного решения» проблемы соотношения вымысла/реальности}

Утрата интереса к операторному подходу Д. Льюиса, по нашему мнению, во многом связана с тем, что другой авторитетный американский философ и теоретик литературы (гватемальского происхождения) Г.-Н. Кастанеда обратил внимание на альтернативные решения проблемы вымысла/ реальности и отдал предпочтение одной из этих альтернатив [5]. Поскольку проблему, по утверждению Кастанеды, удалось решить альтернативным способом, а других достижений операторного подхода в теории литературы на тот момент не было, весомых теоретических оснований развивать и углублять операторный подход не находилось. Рассмотрим же аргументацию Кастанеды.

Свойство предложений менять свой смысл в зависимости от того, встречаются ли они в высказываниях о реальном мире или в художественном тексте, Кастанеда, называет «амбивалентностью» [5, c. 75]. Кроме «операторного решения» Кастанеда выделяет ещё три гипотезы, объясняющие амбивалентность в отношении признака фиктивности/ реальности [5, с. 78]:

(T1) предложение амбивалентно в силу соответствующей амбивалентности предиката;

(T2) предложение амбивалентно в силу амбивалентности субъектных термов;

(Т3) предложение амбивалентно в силу амбивалентности связки.

Сопоставляя аргументы pro et contra каждой теории, Кастанеда отдаёт предпочтение Т3. По его мнению, структурным компонентом, отвечающим за амбивалентность смысла предложения, является именно связка. Кастанеда берёт в качестве примера предложение «Pamela had rented again the old bungalow at 123 Oak Street» («Памела снова сняла старый загородный дом на улице Дубовая 123») и снабжает связку уже знакомыми нам индексами $A$ и $F$. В газетном репортаже, по его мнению, читатель воспринимает предложение «Pamela had $_{A}$ rented again the old bungalow at 123 Oak Street», а в художественном тексте - предложение «Pamela had ${ }_{F}$ rented again the old bungalow at 123 Oak Street» [5, c. 87]. Ответа на вопрос, как читатель узнает, какой индекс «прикрепить» к связке, Кастанеда не даёт.

Особенность позиции Кастанеды состоит в том, что он не отрицает возможности «операторного решение», поскольку оно «содержит абсолютно справедливый тезис: существуют нарративные операторы» [5, с. 83]. Он выдвигает против «операторного решения», по сути, три аргумента.

Контраргумент первый: существуют вымышленные истории, являющиеся общим культурным достоянием, - например, истории о Санте Клаусе: «Многие из нас знают, что Санта Клаус является вымышленным персонажем. Но у нас нет чёткого представления о том, как возник соответствующий вымысел, и мы не знаем, каким именно нарративным операторам следует подчинять предложения о Санте Клаусе. Санта Клаус - это часть нашего общего достояния и не нуждается в нарративных операторах» [5, с. 84]. 
Показательно, что далее Кастанеда сам же «снимает» свой первый контраргумент, признавая: «Мы, несомненно, всегда можем изобрести какойлибо нарративный оператор для тех вымышленных персонажей, который составляют существенную часть нашей жизни. Так, например, существует нейтральное “Говорят, что”. Не исключено, что можно и должно выделить бесконечное множество специальных операторов, относящихся к той же семье, что и “Говорят, что”, - по одному для каждого персонажа, место обитания которого нам уже неизвестно. Заметим ещё раз, как трудно опровергнуть правдоподобную гипотезу» [5, с. 84].

Второй контраргумент Кастанеды связан с миграцией вымышленных персонажей из одного литературного мира в другой (имеются в виду такие персонажи, как Гамлет, Фауст, Дон Жуан, Дон Кихот и другие): «никакой нарративный оператор не может охватить во всей полноте все “жизненные” атрибуты героя» [5, с. 85]. Это очень странный аргумент. Действительно, ни один нарративный оператор не может охватить всю совокупность высказываний о таких сверхпопулярных персонажах, обретающих «независимую жизнь», но каждое конкретное высказывание конкретного лица о таком персонаже находится под действием конкретного нарративного оператора, релевантного тому объёму сведений об этом вымышленном персонаже, которым располагает данное лицо.

Третий контраргумент также связан с вымышленными сущностями, фигурирующими сразу в нескольких художественных произведениях: «вымышленные сущности имеют в таких случаях особый статус вне мира произведений, которые они населяют - в некотором роде подобно людям, которые имеют с ними дело», однако операторная теория, по мнению Кастанеды, «имеет тот недостаток, что она не даёт возможности даже поставить этот вопрос» [5, c. 86]. Далее Кастанеда показывает, как этот вопрос возникает и решается в рамках развиваемой им теории амбивалентности связки. Третий контраргумент весомей двух предыдущих, но мы не будем его опровергать. Мы покажем, что теория амбивалентности связки является мнимой альтернативой операторной теории амбивалентности, а в действительности амбивалентность связки является логическим следствием из «операторного решения», которое оказывается более общим и плодотворным.

\section{4. Синтаксис и семантика}

Физическая аналогия подсказывает, что операторное исчисление наиболее плодотворно там, где удаётся описать реальность с помощью операторов, обладающих какими-то особыми, примечатель- ными свойствами. Например, красота уравнений квантовой механики связана с тем, что наблюдаемые величины описываются самосопряжёнными (эрмитовыми) операторами. Поэтому прежде, чем двигаться дальше, рассмотрим, какими свойствами обладают нарративные операторы.

Первое свойство сразу отметил Льюис: нарративные операторы являются интенсиональными, т.е. смысловыми, семантическими, применение которых требует понимания текста. Однако это далеко не очевидно. Например, обозначим текст роман Сервантеса «Хитроумный идальго Дон Кихот Ламанчский» как T. В процессе чтения каждое предложение из этого романа читатель подвергает действию нарративного оператора «В романе Сервантеса “Дон Кихот”...». Весь процесс чтения романа можно формально представить, как рецепцию одного суперпредложения «Роман Сервантеса "Дон Кихот" гласит, что $T$ ».

Но как на практике читатель узнаёт, какой именно нарративный оператор ему применять? Он узнаёт это из паратекста (паратекстуального аппарата), включающегося перитекст и эпитекст [10, c. 5], а именно - из заголовка, имени автора на обложке, жанрового определения произведения, аннотации, предисловия издателя, биографии автора и других «паратекстуальных элементов». При наличии детализированного паратекста читатель может правильно образовать нарративный оператор, которым следует воздействовать на текст, не читая самого текста, более того - не будучи даже способным понимать этот текст (например, по причине его сложности). Можно представить компьютерную программу, которая бездумно берёт из одной ячейки памяти имя автора (Сервантес), из второй - название произведения («Дон Кихот»), из третьей - жанровое определение (роман), из четвёртой - текст произведения $(T)$, и записывает в пятую ячейку модифицированный текст вида «Роман Сервантеса “Дон Кихот” гласит, что Т». В данном случае действие нарративного оператора на исходный текст происходит, скорее, на синтаксическом, чем на семантическом уровне.

И всё же в более сложных случаях семантическая природа нарративного оператора даёт о себе знать. Рассмотрим случай, описанный Ю.К. Олешей:

«Однажды мне попала в руки книга Шеллера-Михайлова, какой-то роман из собрания сочинений этого писателя, изданный “Нивой”. Я стал читать этот роман - некую историю о денежно-наследственной неудаче в среде не то чиновничьей, не то профессорской... Бойко написано, но ни следа очарования, магии. Свадьбы, векселя, интриги, вдовьи слезы, прожигающие жизнь сынки... И вдруг, перейдя к одной из очередных страниц, я 
почувствовал, как строчки тают перед моими глазами, как исчезает страница, исчезает книга, исчезает комната, и я вижу только то, что изображает автор. Я почти сам сижу на скамейке, под дождем и падающими листьями, как сидит тот, о ком говорит автор, и сам вижу, как идет ко мне грустнаягрустная женщина, как видит ее тот, сидящий у автора на скамейке...

Книжка Шеллера-Михайлова была по ошибке сброшюрована с несколькими страницами того же «Нивского» издания сочинений Достоевского. Страницы были из “Идиота".

Я не знал, что читаю другого автора. Но я почти закричал:

- Что это? Боже мой, кто это пишет? ШеллерМихайлов? Нет! Кто же?

И тут взгляд мой упал на вздрогнувшее в строчке имя Настасьи Филипповны... И вот ещё раз оно в другом месте! Кажущееся лиловым имя, от которого то тут, то там вздрагивали строчки!» [11, c. 746-747].

На этом примере мы видим, как в процессе чтения Олеша переходит от нарративного оператора «В романе Шеллера-Михайлова...» к нарративному оператору «В романе Достоевского “Идиот”...». Для этого необходимо, конечно, понимать текст, - компьютерная программа, автоматически присоединяющая к тексту произведения имя автора и название с обложки, никогда не сможет проделать такой переход. Таким образом, в общем случае нарративный оператор невозможно правильно применить, оставаясь на синтаксическом уровне. Это доказывает семантическую природу нарративного оператора.

\section{5. Нарративно-холистические и нарративно-аналитические операторы}

Важно подчеркнуть, что нарративный оператор даже для конкретного произведения не имеет какого-то фиксированного вида: вид присоединяемого «зачина» определяется конкретной ситуацией. В предыдущем разделе мы показали, что восприятие романа «Дон Кихот» в целом можно формально представить как рецепцию одного суперпредложения «Роман Сервантеса “Дон Кихот" гласит, что Т». Поэтому, если мы исследуем рецепцию текста как чего-то целого (холистический подход), то нас будет интересовать нарративный оператор «Произведение $X$ писателя $Y$ гласит, что...». Нарративные операторы подобного вида мы предлагаем называть холистическими. Холистический подход рассматривает текст как целостную единицу. Отсюда следует важное свойство. Если в суперпредложение «Роман Сервантеса “Дон Кихот” гласит, что Т» мы подставим вместо полного текста романа $T$ текст какой-то его части - например, вставной новеллы «Повесть о безрассудно-любопытном» - суперпредложение станет ложным. Это означает, что нарративно-холистический оператор не обладает свойством линейности, т. е. $\hat{N}\left(T_{1}+T_{2}\right) \neq \hat{N} T_{1}+\hat{N} T_{2}$.

Оператор, рассмотренный Льюисом - «В такомто художественном произведении...»- не является холистическим и, очевидно, обладает свойством линейности, если разбивать исходный текст на части, но не дробить отдельные предложения. На более мелком уровне (на уровне частей предложения) этот нарративный оператор становится неприменимым.

Но можно предложить нарративный оператор особого типа, который сохраняет свойство линейности даже на уровне мельчайших частей предложения. Мы предлагаем называть нарративные операторы с таким свойством нарративно-аналитическими (или нарративно-фрагментарными), поскольку оператор «Фрагмент произведения $X$ гласит, что...» может служить простейшим примером всегда линейного нарративного оператора. Пусть $\hat{n}$ - нарративно-аналитический оператор, тогда при любом разбиении текста истинно, что $\hat{n}\left(T_{1}+T_{2}\right)=\hat{n} T_{1}+\hat{n} T_{2}$ (для простоты записи мы разбили исходный текст на две части, но их может быть сколько угодно). Законность введения нарративно-аналитических операторов состоит в том, что именно их применяют, например, археологи к плохо сохранившимся рукописям или каждый из нас к вырванным из книг страницам.

Для нарративно-аналитических операторов можно доказать ещё одно важное свойство - некоммутативность. В высказывании об актуальном мире (например, в газетном репортаже) может быть процитировано предложение (T) из некоторого художественного произведения - это соответствует ситуации $\hat{n}_{A} \hat{n}_{F} T$. Но в некотором художественном произведении вымышленный персонаж может прочитать в газете идентичное предложение - это соответствует ситуации $\hat{n}_{F} \hat{n}_{A} T$. Очевидно, что смысл предложения $T$ этих ситуациях будет различным: $\hat{n}_{A} \hat{n}_{F} T \neq \hat{n}_{F} \hat{n}_{A} T$, т.е. нарративно-аналитические операторы являются некоммутативными. Аналогично доказывается некоммутативность нарративно-холистических операторов.

Итак, мы установили, что нарративные операторы обладают важными свойствами. Нарративно-холистические операторы являются: 1) семантическими (интенсиональными); 2) некоммутативными; 3) нелинейными. А нарративно-аналитические операторы являются: 1) семантическими (интенсиональными); 2) некоммутативными; 3) линейными. 


\section{6. Снятие контраргументов Г.-Н. Кастанеды}

Вернёмся к примеру Г.-Н. Кастанеды - предложению «Pamela had rented again the old bungalow at 123 Oak Street» («Памела снова сняла старый загородный дом на улице Дубовая 123»), имеющему различный смысл в газетном репортаже и художественном произведении. Операторный подход показывает, как появляются различные индексы A и F у связки had в этих случаях. В первом случае рассматриваемое предложение находится под действием нарративно-аналитического оператора $\hat{n}_{A}$ (добавляющего зачин «Фрагмент высказывания о реальности гласит, что...»):

$\hat{n}_{A}$ «Pamela had rented again the old bungalow at 123 Oak Street» $=\hat{n}_{A}$ «Pamela» $+\hat{n}_{A}$ «had» $+\hat{n}_{A}$ «rented» $+\hat{n}_{A}$ «again the old bungalow at 123 Oak Street».

Во втором случае рассматриваемое предложение находится под действием фрагментарного нарративного оператора $\hat{n}_{F}$ (добавляющего зачин «Фрагмент высказывания о вымышленном мире гласит, что...»):

$\hat{n}_{F}$ «Pamela had rented again the old bungalow at 123 Oak Street» $=\hat{n}_{F}$ 《Pamela» $+\hat{n}_{F}$ «had» $+\hat{n}_{F}$ «rented» $+\hat{n}_{F}$ «again the old bungalow at 123 Oak Street».

Здесь $\hat{n}_{A}$ «had» и $\hat{n}_{F}$ «had»- это то же самое, что Кастанеда обозначает $\operatorname{had}_{A}$ и $\operatorname{had}_{F}$ Амбивалентность связки, не объяснённая Кастанедой, получает элементарное объяснение с помощью операторного подхода. Иными словами теория амбивалентности Кастанеды является логическим следствием отвергаемой им операторной теории амбивалентности. То же самое можно сказать и о теориях Т1 и Т2, поскольку и предикат, и субъектный терм также находятся под действием нарративно-аналитического оператора. Выходит, что Кастанеда не зря находил теории Т1 и Т2 «правдоподобными», хотя отдавал предпочтение теории Т3, - все три теории являются логическими следствиями из операторной теории амбивалентности (Т4), следовательно все три верны, если верна Т4.

Теория Кастанеды является мнимой альтернативой операторной теории амбивалентности - она является её логическим следствием. Ошибка Кастанеды проистекала из того, что он считал все нарративные операторы холистическими, и не догадывался о существовании нарративно-аналитических (нарративно-фрагментарных) операторов, обладающих свойством линейности вплоть до уровня отдельных частей предложения.

\section{7. Нарративный оператор нарратора}

В предыдущих разделах мы говорили о нарративных операторах, ввёденных Д. Льюисом, которые можно охарактеризовать как нарративные опера- торы произведения или нарративные операторы автора - они имеют вид «Произведение Y автора X, гласит, что...» (нарративно-холистический оператор) и «Фрагмент произведения $\mathrm{Y}$ автора $\mathrm{X}$ гласит, что...» (нарративно-аналитический оператор).

Но при анализе художественных произведений, по нашему мнению, целесообразно рассматривать также иные типы нарративных операторов. В самом деле, во многих художественных произведениях повествование ведётся от лица рассказчика (нарратора), не идентичного автору произведения. Даже если рассказчик носит то же самое имя, что и автор произведения, его следует рассматривать как лирического двойника автора - он может быть неидентичен реальному автору, например, биографически или характерологически. Так, новелла Э.Т.А. Гофмана «Пустой дом» (1816) написана от первого лица и в ней описан реально существующий дом, расположенный по адресу: Берлин, улица Унтер-ден-Линден, № 9. Но сама история, очевидно, вымышлена - следовательно, Гофман-нарратор, с которым эта история произошла, неидентичен Гофману-автору. Таким образом, текст Тэтой новеллы находится под действием сразу двух нарративных операторов: «Новелла Гофманаавтора «Пустой дом» гласит, что рассказчик (Гофманнарратор) сообщает, что T». Первый нарративный оператор в данном случае - нарративный оператор произведения (или нарративный оператор автора), второй нарративный оператор - это нарративный оператор нарратора. На следующем примере мы можем увидеть это различие более наглядно.

Скажем, роман Э.Т.А. Гофмана «Эликсиры дьявола» (1815-1816) состоит из четырёх частей: 1) предисловие издателя; 2) рукопись Медардуса, включающая письмо княжны-настоятельницы и письмо Аврелии; 3) примечания издателя, включающего «Пергамент старого живописца»; 4) послесловия монаха Спиридона.

Нарративная структура романа в обозначениях Ю.И. Левина [12, с. 45] будет выглядеть следующим образом: «ГОФМАН: $\quad$ i: $\left\{\mathrm{t}_{1}\right\}, \mathrm{m}:\left\{\mathrm{t}_{2}\right\}$, i: $\left\{\mathrm{t}_{3}\right\}, \mathrm{m}:\left\{\mathrm{t}_{4}\right\}$, s: $\left.\left\{\mathrm{t}_{5}\right\}\right\} »$. Символ перед фигурными скобками обозначает нарратора, а в фигурные скобки заключён текст, являющийся повествованием данного нарратора, а именно: $t_{1}$ - предисловие издателя (i); $\mathrm{t}_{2}$ - рукопись Медардуса (m); $\mathrm{t}_{3}$ - примечание издателя; $\mathrm{t}_{4}$ - продолжение рукописи Медардуса; $\mathrm{t}_{5}$ - послесловие монаха Спиридона (s), библиотекаря в монастыре капуцинов.

Легко убедиться, что предложенная нами операторная нотация гораздо удобней:

$$
\hat{N}_{\text {HOFFMAN }}\left(\hat{N}_{i} t_{1}+\hat{N}_{m} t_{2}+\hat{N}_{i} t_{3}+\hat{N}_{m} t_{4}+\hat{N}_{s} t_{5}\right) .
$$

В предыдущей нашей статье нами показано, как принятие во внимание нарративного опера- 
тора нарратора влияет на реконструкцию фабулы романа - оказывается, что она может быть реконструирована двояким образом [13]. Таким образом, в некоторых случаях введение и использование нарративного оператора нарратора позволяет нам глубже понять творческий замысел автора.

\section{8. Нарративный оператор персонажа}

Д. Льюис в той же статье, в которой вводит нарративные операторы, ставит проблему, разрешить которую он, по собственному признанию, не может. Он называет её «загадка хвастливого скотовода» [7, c. 67].

В некотором произведении некий певец поёт песню, в которой говорится: «Я скотовод по ремеслу, а зовут меня Гадкий Дейв. Я старый и седой и одноглазый. На дворе я, конечно, искусен, но стоит посадить меня на коня, и я поеду, куда многие молодые не осмелятся <...> На самом деле, я повелеваю всем, чёрт возьми!».

Далее Льюис замечает: «Это вымысел внутри вымысла: вымыслы Гадкого Дейва сами по себе являются вымыслом, а его хвастовство - притворным говорением правды. В вымысле внутри вымысла он действительно является повелителем всего. Во внешнем художественном вымысле это не так, он только утверждает это. Этот вымысел в вымысле сам по себе не составляет проблемы. Но рядом лежит настоящая проблема, и я не могу предложить никакого решения. Почему этот вымысел в вымысле не рушится? Когда певец делает вид, что он Гадкий Дейв, делающий вид, что он рассказывает о самом себе правду, то как это отличается от того, как если бы он делал вид, что он Гадкий Дейв, действительно рассказывающий о самом себе правду? Должно иметь место первое, а не второе; иначе мы должны были бы заключить, что нет никакого вставленного художественного вымысла и во внешнем вымысле - теперь единственном вымысле - истинно, что Гадкий Дейв повелевает всем и рассказывает нам об этом. Это значило бы совсем не ухватить сути дела. Мы должны отличать то, когда кто-то делает вид, что делает вид, от того, когда он действительно делает вид. Интуитивно кажется, что мы в состоянии различить эти случаи, но как следует это анализировать?» [7, с. 67-68]. Этим вопросом заканчивается статья.

Мы ответим на этот вопрос с помощью операторного подхода, предложенного самим Льюисом. Вымысел в вымысле означает лишь то, что текст находится под действием сразу нескольких операторов вымысла (fiction-operator). В примере, приведенным Льюисом, предложение «На самом деле, я повелеваю всем, черт возьми!» (T) находится под действием сразу трёх операторов: 1) нарративного оператора произведения («В произведении, процитированном Д. Льюисом, говорится, что...»); 2) нарративного оператора нарратора - это в данном случае певец («В песне певца говорится, что ...»); 3) нарративного оператора персонажа этой песни Гадкого Дейва («Персонаж Гадкий Дейв говорит, что ...»). Мы видим три типа вложенных друг в друга нарративных операторов: нарративный оператор произведения (автора), нарративный оператор нарратора (певца), нарративный оператор персонажа (Гадского Дейва).

Вообще говора, реплика $T$ любого персонажа в художественном произведении должна быть рассматриваема как находящаяся под действием нарративного оператора данного персонажа. В операторной записи:

$$
\hat{N}_{\text {AUTHOR }} \hat{N}_{\text {NARRATOR }} \hat{N}_{\text {CHARACTER }} T .
$$

Скажем, персонаж романа Ф.М. Достоевского «Бесы» Степан Трофимович Верховенский говорит: «Сама наука не простоит пять минут без красоты». Но читатель, встречая это предложение, не воспринимает его изолированно - читатель помнит, что читает роман Достоевского, в котором повествование ведётся от лица анонимного рассказчика («хроникёра») и что данную реплику произносит персонаж романа. Таким образом, по сути, он воспринимает модифицированное предложение: «Фрагмент романа Ф.М. Достоевского “Бесы” гласит, что хроникёр сообщает, что Степан Трофимович Верховенский говорит, что сама наука не простоит пять минут без красоты». Нельзя, следовательно, заключить, что Достоевский полагал, что сама наука не простоит пять минут без красоты, - нельзя даже утверждать, что Степан Трофимович сказал дословно: «Сама наука не простоит пять минут без красоты». Можно лишь утверждать, что хроникёр в романе Достоевского приписывает Степану Трофимовичу Верховенскому фразу «Сама наука не простоит пять минут без красоты», но не исключено, что хроникёр плохо расслышал слова Степана Трофимовича (возможно, что хроникёру только показалось, что Степан Трофимович сказал именно это, а не что-то другое).

Читатель отличает «внутренний вымысел» в вымысле, поскольку при чтении текста «вымысла в вымысле» подвергает его действию дополнительного нарративного оператора. Если этот «внутренний вымысел» исходит от персонажа - то это нарративный оператор данного персонажа. Из слов персонажа читатель заключает, что претензии Гадкого Дейва чрезмерны для простого скотовода, т.е. налицо хвастовство. Затем весь текст, находящийся под действием нарративного оператора данного 
персонажа, читатель интерпретирует с учётом догадки о характерной особенности данного персонажа (хвастливости). Таким образом, «загадка хвастливого скотовода», поставленная Льюисом, легко решается небольшим расширением предложенного Льюисом операторного подхода.

\section{9. Область применения операторного подхода в теории литературы}

Первая важная область применения операторного подхода в теории - это реконструкция и формализация процесса художественного творчества. Г.-Н. Кастанеда предвидел такую возможность, но не продвинулся по этому пути: «Сочинение истории или художественного произведения - это не что иное, как одно из возможных состояний сознания, когда класс $\lambda$ положений дел или пропозиций, некоторые из которых выдуманы, мыслятся как единый класс, и именно это состояние сознания эмпирически подчиняет члены класса $\lambda$ одному или нескольким нарративным операторам» [5, с. 87].

Вторая важная область - это реконструкция и формализация процесса рецепции художественного произведения, его интерпретации. Примером такой рецепции и интерпретации может служить литературная критика, - таким образом открывается возможность формализации этой пока недостаточно объяснённой и слабо формализованной деятельности $[14 ; 15]$. Ключевая идея состоит в том, чтобы рассматривать рецепцию текста как протекающую в несколько этапов, а каждый этап рассматривать как применение к исходному тексту (или результату предыдущего этапа) некоторого семантического (интенсионального) оператора. Тогда интерпретацию некоторого текста можно представить как результат воздействия на исходный текст $\left(\mathrm{T}_{1}\right)$ последовательности n интенсиональных операторов:

$$
T_{2}=\hat{I}_{n} \ldots \hat{I}_{3} \hat{I}_{2} \hat{I}_{1} T_{1} \text {. }
$$

Справедливо ли это в общем случае, нам неизвестно, но, например, для отдельных литератур- но-критических методов это справедливо, хотя бы уже потому, что такое методы можно сконструировать. Такие литературно-критические методы можно определить как применение к исходному тексту некоторой конечной последовательности заданных интенсиональных операторов. Примером может служить предложенный нами формальный литературно-критический метод - «алгокритика» [15].

Другой пример - это возможность объяснить различие художественных текстов по «реалистичности» (и вообще феномен художественного реализма) как результат применения читателем особых семантических операторов [16].

Можно предположить, что много открытий сулит и углубление аналогии между операторным подходом в теории литературы и операторным исчислением в математике и физике (особенно в квантовой механике). К сожалению, это требует свободного владения математическим аппаратом операторного исчисления. Мало кто из гуманитариев (включая автора этих строк) может похвастаться, что владеет этим навыком в достаточной степени.

\section{0. Заключение}

Мы продемонстрировали, что операторный подход даёт самое элегантное и убедительное решение проблемы амбивалентности предложений по признаку вымысел/реальность. Операторная теория амбивалентности обладает большей логической силой и общностью, чем альтернативные теории, и, таким образом, является перспективной областью исследований. Можно прогнозировать, что применение операторного подхода окажется плодотворным в таких актуальных областях современной теории литературы, как объяснение процесса художественного творчества и объяснение процесса рецепции/интерпретации художественного произведения.

\section{Список литературы:}

1. Coquet J.-C. Sémiotique littéraire. Paris: Jean-Pierre Delarge et Mame, 1973. 268 p.

2. Ryan M.-L. The Modal Structure of Narrative Universes // Poetics Today. 1985. Vol. 6. № 4. P. 717-755.

3. Ronen R. Possible worlds in literary theory. Cambridge: Cambridge University Press, 1994. 244 p.

4. Бойко М.Е. Типологические и структурные особенности фабулы кинопроизведений второй половины XX - начала XXI века: Дис. ... канд. искусствоведения. М., 2014. 191 с.

5. Кастанеда Г.-Н. Художественный вымысел и действительность // Логос. 1999. № 3. С. 69-102.

6. Lewis D. Philosophical Papers. Vol. I. New York, Oxford: Oxford University Press, 1983. 304 p.

7. Льюиз Д. Истинность в вымысле // Логос. 1999. № 3. С. 48-68.

8. Вежбицка А. Метатекст в тексте // Новое в зарубежной лингвистике. Вып. VIII. Лингвистика текста. М.: Прогресс, 1978. С. 402-421.

9. Нейман И. фон. Математические основы квантовой механики. М.: Наука, 1964. 368 с.

10. Genette G. Paratexts: Thresholds of Interpretation. Cambridge: Cambridge University Press, 1997. 456 p.

11. Олеша Ю.К. Заговор чувств: Романы. Рассказы. Пьесы. Статьи. Воспоминания. Ни дня без строчки. СПб.: Кристалл, $1999.848 \mathrm{c.}$ 


\section{Филология: научные исследования 3(23) • 2016}

12. Левин Ю.И. Повествовательная структура как генератор смысла: текст в тексте у Х.Л. Борхеса // Труды по знаковым системам. Вып. 14. Тарту: Тартуский государственный университет, 1981. С. 45-64.

13. Бойко М.Е. Личность нарратора и реконструкция фабулы романа Э.Т.А. Гофмана «Эликсиры дьявола» // Филологические науки. Вопросы теории и практики. 2014. № 11. Ч. 1. С. 31-34.

14. Бойко М.Е. Формализация литературно-критической деятельности // Культура и искусство. 2011. № 6. С. 112-115.

15. Бойко М.Е. Алгокритика как формальный метод // Филологические науки. Вопросы теории и практики. 2016. № 3. Ч. 2. С. 14-17.

16. Бойко М.Е. Реализм и трёхоператорный метод интерпретации // Филология: научные исследования. 2015. C. 224-228.

\section{References (transliterated):}

1. Coquet J.-C. Sémiotique littéraire. Paris: Jean-Pierre Delarge et Mame, 1973. 268 p.

2. Ryan M.-L. The Modal Structure of Narrative Universes // Poetics Today. 1985. Vol. 6. № 4. P. 717-755.

3. Ronen R. Possible worlds in literary theory. Cambridge: Cambridge University Press, 1994. 244 p.

4. $\quad$ Boiko M.E. Tipologicheskie i strukturnye osobennosti fabuly kinoproizvedenii vtoroi poloviny XX - nachala XXI veka: Dis.... kand. iskusstvovedeniya. M., 2014. 191 s.

5. Kastaneda G.-N. Khudozhestvennyi vymysel i deistvitel'nost' // Logos. 1999. № 3. S. 69-102.

6. Lewis D. Philosophical Papers. Vol. I. New York, Oxford: Oxford University Press, 1983. 304 p.

7. L'yuiz D. Istinnost' v vymysle // Logos. 1999. № 3. S. 48-68.

8. Vezhbitska A. Metatekst v tekste // Novoe v zarubezhnoi lingvistike. Vyp. VIII. Lingvistika teksta. M.: Progress, 1978. S. $402-421$.

9. Neiman I. fon. Matematicheskie osnovy kvantovoi mekhaniki. M.: Nauka, 1964. 368 s.

10. Genette G. Paratexts: Thresholds of Interpretation. Cambridge: Cambridge University Press, 1997. 456 p.

11. Olesha Yu. K. Zagovor chuvstv: Romany. Rasskazy. P’esy. Stat'i. Vospominaniya. Ni dnya bez strochki. SPb.: Kristall, 1999. $848 \mathrm{~s}$.

12. Levin Yu.I. Povestvovatel'naya struktura kak generator smysla: tekst v tekste u Kh.L. Borkhesa // Trudy po znakovym sistemam. Vyp. 14. Tartu: Tartuskii gosudarstvennyi universitet, 1981. S. 45-64.

13. Boiko M.E. Lichnost' narratora i rekonstruktsiya fabuly romana E.T.A. Gofmana «Eliksiry d'yavola» // Filologicheskie nauki. Voprosy teorii i praktiki. 2014. № 11. Ch. 1. S. 31-34.

14. Boiko M.E. Formalizatsiya literaturno-kriticheskoi deyatel'nosti // Kul'tura i iskusstvo. 2011. № 6. S. 112-115.

15. Boiko M.E. Algokritika kak formal'nyi metod // Filologicheskie nauki. Voprosy teorii i praktiki. 2016. № 3. Ch. 2. S. $14-17$.

16. Boiko M.E. Realizm i trekhoperatornyi metod interpretatsii // Filologiya: nauchnye issledovaniya. 2015. № 3. S. $224-228$. 